\title{
Anterolateral Prefrontal Cortex Mediates the Analgesic Effect of Expected and Perceived Control over Pain
}

\author{
Katja Wiech, ${ }^{*}$ Raffael Kalisch, ${ }^{*}$ Nikolaus Weiskopf, Burkhard Pleger, Klaas Enno Stephan, and Raymond J. Dolan \\ Wellcome Department of Imaging Neuroscience, Institute of Neurology, London WC1N 3BG, United Kingdom
}

\begin{abstract}
Perceived control attenuates pain and pain-directed anxiety, possibly because it changes the emotional appraisal of pain. We examined whether brain areas associated with voluntary reappraisal of emotional experiences also mediate the analgesic effect of perceived control over pain. Using functional magnetic resonance imaging, we compared self-controlled noxious stimuli with physically identical stimuli that were externally controlled. Self-controlled stimulation was accompanied by less pain and anxiety and higher activation in dorsal anterior cingulate (dACC), right dorsolateral, and bilateral anterolateral prefrontal (alPFC) cortices. Activation in dACC and right alPFC was negatively correlated with pain intensity ratings. For externally controlled pain, activation in right alPFC was inversely correlated with the participants' general belief to have control over their lives. Our results are consistent with a reappraisal view of control and suggest that the analgesic effect of perceived control relies on activation of right alPFC. Failure to activate right alPFC may explain the maladaptive effects of strong general control beliefs during uncontrollable pain.
\end{abstract}

Key words: pain; fMRI; prefrontal cortex; cognitive; emotion; analgesia

\section{Introduction}

Pain research has established that both acute and chronic pain are perceived as less intense when they are or appear to be controllable (Weisenberg et al., 1985; Scharff et al., 1995; Pellino and Ward, 1998). Accordingly, perceived control has been shown to attenuate brain responses to pain (Salomons et al., 2004; Mohr et al., 2005). It has been proposed that perceived control attenuates pain because it changes the "meaning" of pain, making it less threatening (Arntz and Schmidt, 1989). After this view, pain is appraised differently (is "reappraised") when controllable.

Emotion regulation research has found ample evidence that a voluntary and consciously controlled form of reappraisal (reinterpretation) can attenuate aversive emotional reactions (Gross, 2002), including peripheral and neural reactivity to pain (Kalisch et al., 2005). This raises the possibility that, in humans, voluntary reappraisal efforts contribute to the analgesic effects of perceived control. On this basis, we asked whether a network of dorsal medial and lateral prefrontal areas implicated in voluntary reappraisal (Kalisch et al., 2005; Ochsner and Gross, 2005) mediates aspects of analgesia resulting from perceived control in normal human subjects.

To address this question, we used functional magnetic resonance imaging (fMRI) to measure brain responses to selfcontrolled and externally controlled painful stimulation (see Fig. 1). During self-controlled trials, participants were able to stop an

Received June 19, 2006; revised Aug. 25, 2006; accepted Sept. 23, 2006.

This work was supported by a grant from the Wellcome Trust Program (R.J.D.), German Research Society Grant Wi 1957/2-1 (K.W.), and a European Union Marie Curie Individual Fellowship and Presencia programme (R.K.). We thank Pia Rotshtein, Christian Ruff, and Jeremie Mattout for very helpful discussions.

${ }^{*}$ K.W. and R.K. contributed equally to this work.

Correspondence should be addressed to Dr. Katja Wiech, Pain Imaging Neuroscience Group, Department of Human Anatomy and Genetics, University of 0xford, South Parks Road, 0xford OX1 30X, UK. E-mail: katja.wiech@anat.ox.ac.uk. DOl:10.1523/JNEUROSCI.2568-06.2006

Copyright $\odot 2006$ Society for Neuroscience $\quad$ 0270-6474/06/2611501-09\$15.00/0 ongoing train of painful electric stimuli when the pain became intolerable. During externally controlled trials, participants were told that the train of stimuli would either be stopped at some point by another person (external control by a "powerful other") or by a computer that followed a random sequence (external control by "chance/fate"). The stimulation during the externally controlled trials was yoked to the self-controlled trials such that the participants received the same number and intensity of stimuli in both conditions (see Materials and Methods). At the end of each stimulation period, participants rated the perceived mean intensity of the stimulation during the previous trial. Ratings of the average anxiety perceived during painful stimulation in the three conditions were given at the end of the experiment. Subjects also provided a measure of their degree of belief in control over life as assessed by a questionnaire administered before the experiment.

We hypothesized that factual controllability in the selfcontrolled trials would attenuate the subjective intensity of pain and that this would be associated with activation in voluntary reappraisal-related brain areas. We specifically predicted activation in the contrast "self-controlled - externally controlled pain" in a right anterolateral prefrontal cortex (alPFC) area proposed recently by us (Kalisch et al., 2006b) as being crucial for reappraisal. We further predicted that activation in this area would be negatively correlated with subjective pain intensity. Finally, we explored whether and how the relationship between controllability and a control-related brain response would be moderated by the individual control belief.

\section{Materials and Methods}

Subjects. Twelve healthy female right-handed subjects, aged 20-29 years (mean \pm SD, $24 \pm 3.08$ years) consented to take part in the study, which was approved by the Joint National Hospital for Neurology and Neuro- 

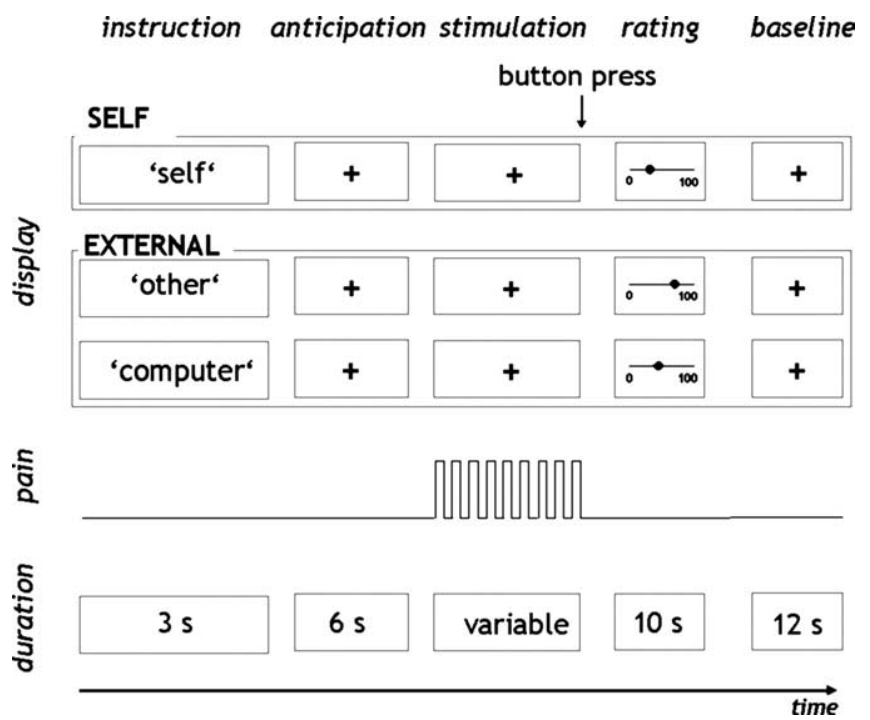

Figure 1. Design of the study. Participants were subjected to noxious electrical stimuli that were either controlled by themselves (self-controlled) or externally controlled. At the beginning of each trial, participants were informed, on the computer screen, about the locus of control over the upcoming pain stimulation (instruction). During the next $6 \mathrm{~s}$, participants were awaiting the beginning of the stimulation (anticipation). In selfcontrolled trials, the ongoing painful stimulation was terminated by a button press of the participant. In the externally controlled condition, the number of stimuli applied was predetermined by the self-controlled trials (see Materials and Methods), and participants were instructed to press the button immediately after the stimulation had stopped. Subsequently, the mean subjective pain intensity was rated via the computer display (rating). Each trial was accomplished by a $12 \mathrm{~s}$ baseline period (baseline).

surgery/Institute of Neurology Ethics Committee. Subjects were free from medication and neurological and psychiatric history.

Experimental design. In the present study, noxious electrical stimuli were applied under three conditions: (1) when participants themselves could stop the stimulation ("self-controlled condition"), (2) when participants believed that the stimulation was controlled by another person ("other-controlled condition"), and (3) when the stimulation was thought to be controlled by a computer that followed a random sequence ("computer-controlled condition"; see below) (Fig. 1). The experiment was divided into four sessions with four repetitions (trials) of the three conditions per session. Each condition was thus repeated 16 times. These experimental sessions were preceded by a short practice run.

Before the onset of the stimulation, subjects were presented with the word "self," "other," or "computer," which was displayed on a computer screen in the MRI scanner for $3 \mathrm{~s}$. The display "self" announced that, during this trial, the subjects themselves would be able to stop the repetitive application of painful stimulation at any time after stimulation onset by pressing a button with their right index finger (self-controlled condition). The button press stopped the stimulation immediately. The subjects were informed that the stimulation would go on indefinitely if they did not press the button.

The display "other" signaled that a second subject sitting in the MRI control room would stop the stimulation at some point and that nobody else could interfere with this (other-controlled condition). In fact, participants received the same number of stimuli they had chosen themselves in one of the previous trials of the self-controlled condition (see below, Stimulation).

In the computer-controlled condition (display "computer"), participants expected a computer in the control room to stop the ongoing stimulation. They were instructed that the computer determined the number of stimuli by a randomization program. As in the othercontrolled condition, the number of stimuli was predefined by the selfcontrolled condition (see below, Stimulation).

During the application of the stimuli, subjects were instructed to fixate a white cross that was displayed in the center of the computer screen.
Stimulation. Before the first session, individual current levels were determined and were adjusted between sessions if necessary (see below, Experimental protocol). The mean \pm SD stimulation intensity was $2.61 \pm 0.87 \mathrm{~mA}$. The stimuli were applied to the back of the left hand using a commercial electric stimulation device (Constant Current Stimulator, model DS7A; Digitimer, Hertfordshire, UK) delivering trains of $200 \mathrm{~ms}$ monopolar square waveform pulses via a silver chloride electrode (interstimulus interval, $500 \mathrm{~ms}$ ). Because we aimed to apply the identical stimulation in all three conditions, the number of stimuli delivered per trial in the two external conditions (i.e., other-controlled and computercontrolled) were determined by the number of stimuli participants had chosen in the previous self-controlled trials. On average, participants stopped the stimulation after $37 \pm 17.61$ stimuli (mean \pm SD; minimum of 13 and maximum of 99 stimuli).

In the first session, the two self-controlled trials had to precede the externally controlled trials to get a sample of chosen stimulation durations for the following externally controlled trials. In the following sessions, the number of stimuli per trial applied in the externally controlled conditions was taken from the self-controlled trials of the previous session. For instance, if the subject had stopped the stimulation after the 10th stimulus in the first trial and after the 13th stimulus in the second trial of the second session, she received 10 and 13 stimuli in the two externally controlled trials of the third session. This procedure allowed for a fully randomized presentation of conditions, i.e., the two externally controlled conditions could be presented before as well as after the selfcontrolled trials. As a consequence, we can exclude order effects.

To control for motor responses that occurred in the self-controlled conditions, subjects also had to press a button at the end of the stimulus trains in the externally controlled conditions. They were cued by an enlargement of the fixation cross to press the button as quickly as possible. The large white cross appeared immediately after the stimulation had stopped.

Trial-by-trial rating of subjective stimulation intensity. At the end of each trial, subjects rated the average perceived mean intensity of the stimulation during the previous trial on a numerical rating scale ranging from 0 (not painful at all) to 100 (strongest imaginable pain) that was presented on the computer screen. The rating was given via a pointer that could be moved in both directions along the scale by holding either of two buttons pressed. Analgesic effects were inferred if average pain ratings in a given condition were significantly lower $(p=0.05)$ than in a comparison condition. This operational definition of analgesia follows a general definition of analgesia as "a deadening or absence of the sense of pain without loss of consciousness" (Stedman, 1995).

Rating of anxiety. At the end of the experiment, participants gave a rating of how anxious they felt during each of the three conditions on a scale from 0 (not anxious at all) to 10 (extremely anxious).

Control belief questionnaire. To assess the general belief about who or what has an influence on one's own life, participants were asked to fill in the "I, P, and C Scales" by Levenson (1981) before scanning. This questionnaire contains a scale (I scale) that measures the extent to which people believe that they have control over their own life. The I scale comprises an eight-item subscale with a seven-point Likert response format $(0-6)$. A high score on the I scale indicates a strong control belief.

Experimental protocol. On arrival, subjects were provided with written task instructions and gave their informed consent. Subjects were then brought to the MR control room in which they were familiarized with the instructions displayed on the computer screen during the experiment and with the rating procedure. They were told that the second person who was supposed to control the stimulation in the other-controlled condition would be instructed at the same computer while they themselves were prepared for the scanning sessions inside the MR room.

Before the subjects were positioned in the MR scanner, the individual stimulation levels were determined within the scanner room. To find an individual level for electrical stimulation, trains of 10 200-ms stimuli of increasing intensities were applied. After each train, the subject gave a verbal intensity rating between 0 and 100 . The calibration procedure stopped when participants rated the intensity as 70 . Current levels that were rated as 70 were taken for stimulation during the experiment. To 
Table 1. Brain responses to self-controlled and externally controlled pain (main effect of pain; $p<0.001$ uncorrected)

\begin{tabular}{|c|c|c|c|c|c|c|c|}
\hline \multirow[b]{2}{*}{ Brain region } & \multirow[b]{2}{*}{ Laterality } & \multirow[b]{2}{*}{ Brodmann area } & \multicolumn{3}{|c|}{ MNI coordinates } & \multirow[b]{2}{*}{ Cluster size (voxel) } & \multirow[b]{2}{*}{ Zscore } \\
\hline & & & $x$ & $y$ & $z$ & & \\
\hline \multirow[t]{9}{*}{ Insula/operculum/temporal lobe } & $\mathrm{R}$ & 48 & 57 & 0 & 3 & 871 & 4.98 \\
\hline & $\mathrm{R}$ & 48 & 45 & 6 & -9 & & 4.88 \\
\hline & $\mathrm{R}$ & 48 & 54 & 18 & 9 & & 4.75 \\
\hline & $\mathrm{L}$ & 48 & -39 & -18 & 15 & 18 & 4.27 \\
\hline & $\mathrm{L}$ & 48 & -42 & 3 & -9 & 183 & 4.10 \\
\hline & $\mathrm{L}$ & 38 & -54 & 6 & -6 & & 4.02 \\
\hline & $\mathrm{L}$ & 48 & -57 & -3 & 6 & & 4.01 \\
\hline & $\mathrm{L}$ & 48 & -36 & 0 & 9 & 4 & 3.90 \\
\hline & L & 48 & -54 & -18 & 12 & 9 & 3.82 \\
\hline \multirow[t]{2}{*}{ Pallidum } & $\mathrm{L}$ & & -15 & 6 & 0 & 48 & 4.55 \\
\hline & $\mathrm{R}$ & & 15 & 6 & -3 & 2 & 3.21 \\
\hline \multirow[t]{3}{*}{ Caudate nucleus } & $\mathrm{L}$ & & -15 & 18 & 6 & & 3.43 \\
\hline & $\mathrm{R}$ & & 12 & 9 & 15 & 10 & 3.45 \\
\hline & $\mathrm{R}$ & & 12 & 12 & 3 & & 3.23 \\
\hline \multirow[t]{3}{*}{ SII } & $\mathrm{L}$ & 48 & -51 & -24 & 27 & 13 & 3.96 \\
\hline & $\mathrm{L}$ & 48 & -63 & -27 & 21 & & 3.34 \\
\hline & $\mathrm{R}$ & 48 & 51 & -45 & 33 & 7 & 3.38 \\
\hline \multirow[t]{4}{*}{ OFC } & $\mathrm{R}$ & 47 & 51 & 42 & -9 & 6 & 3.86 \\
\hline & $\mathrm{R}$ & 11 & 24 & 30 & -15 & 15 & 3.77 \\
\hline & $\mathrm{L}$ & 11 & -24 & 39 & -9 & 12 & 3.82 \\
\hline & $\mathrm{L}$ & 11 & -21 & 21 & -6 & 3 & 3.61 \\
\hline \multirow[t]{3}{*}{ Inferior parietal lobe/SII } & $\mathrm{L}$ & 40 & -57 & -42 & 36 & 45 & 3.85 \\
\hline & $\mathrm{L}$ & 40 & -57 & -42 & 45 & & 3.49 \\
\hline & $\mathrm{L}$ & 48 & -48 & -42 & 27 & & 3.47 \\
\hline $\mathrm{ACC}$ & $\mathrm{R} / \mathrm{L}$ & 25 & 0 & 31 & 2 & 6 & 3.77 \\
\hline
\end{tabular}

L, Left; R, right; SIll, secondary somatosensory cortex. $p<0.001$ uncorrected at voxel level; voxel size, $2 \times 2 \times 2 \mathrm{~mm}$.

Table 2. Brain responses to externally controlled compared with self-controlled pain ( $p<0.001$ uncorrected)

\begin{tabular}{|c|c|c|c|c|c|c|c|}
\hline \multirow[b]{2}{*}{ Brain region } & \multirow[b]{2}{*}{ Laterality } & \multirow[b]{2}{*}{ Brodmann area } & \multicolumn{3}{|c|}{ MNI coordinates } & \multirow[b]{2}{*}{ Cluster size (voxel) } & \multirow[b]{2}{*}{ Zscore } \\
\hline & & & $x$ & $y$ & $Z$ & & \\
\hline \multirow[t]{6}{*}{ OFC } & $\mathrm{R}$ & 11 & 27 & 30 & -15 & 4 & 3.54 \\
\hline & $\mathrm{R}$ & 47 & 45 & 33 & -12 & 3 & 3.27 \\
\hline & $\mathrm{R}$ & 47 & 27 & 45 & 0 & 2 & 3.26 \\
\hline & L & 47 & -45 & 33 & -15 & 3 & 3.46 \\
\hline & $\mathrm{L}$ & 47 & -27 & 30 & -15 & 3 & 3.43 \\
\hline & $\mathrm{L}$ & 11 & -15 & 45 & -15 & 1 & 3.18 \\
\hline Temporal lobe & L & 20 & -54 & -21 & -24 & 2 & 3.52 \\
\hline $\mathrm{ACC}$ & $\mathrm{R}$ & 25 & 9 & 33 & 3 & 3 & 3.41 \\
\hline Cerebellum & $\mathrm{R}$ & & 15 & -87 & -36 & 2 & 3.23 \\
\hline MPFC & $\mathrm{L}$ & 9 & -3 & 45 & 36 & 1 & 3.23 \\
\hline
\end{tabular}

L, Left; R, right; MPFC, medial prefrontal cortex. $p<0.001$ uncorrected at voxel level; voxel size, $2 \times 2 \times 2 \mathrm{~mm}$.

account for sensitization or habituation processes, current levels were readjusted before each session. A pulse oximeter (Nonin 8600FO; Nonin Medical, Plymouth, MN) attached to the left index finger monitored the heart rate throughout the experiment. Before the four experimental sessions and after the subject had been positioned in the scanner, a short practice run was performed.

Image acquisition. The functional imaging was conducted by using a 3T MRI head scanner (Magnetom Allegra; Siemens, Erlangen, Germany) to acquire gradient echo $\mathrm{T} 2{ }^{*}$-weighted echo-planar images (EPIs) with blood oxygenation level-dependent contrast (repetition time, $2.86 \mathrm{~s}$; echo time, $30 \mathrm{~ms}$; flip angle, $90^{\circ}$; matrix, $64 \times 64$; field of view, $192 \times 192 \mathrm{~mm}^{2}$ ). We used a special sequence designed to optimize EPI data acquisition in the orbitofrontal cortex (OFC) (Deichmann et al., 2003) in which the slices were tilted in an oblique orientation at $30^{\circ}$ to the transverse plane and which used a $z$-shim gradient preparation pulse of $-1.3 \mathrm{mT} \cdot \mathrm{m}^{-1} \cdot \mathrm{ms}^{-1}$. Each volume comprised 44 contiguous axial $2-\mathrm{mm}$-thick slices with $1 \mathrm{~mm}$ gap. Because the duration of each session was dependent on the number of stimuli chosen by the individual subject, the number of volumes acquired varied between sessions and subjects.
A standard coil was used that was packed with foam pads. Subjects had to wear MRcompatible pneumatic headphones to attenuate scanner noise. For display purposes, a highresolution $\left(1 \times 1 \times 1 \mathrm{~mm}^{3}\right.$ voxel size $)$ T1weighted structural MRI was acquired (threedimensional modified driven equilibrium Fourier transformation; 176 partitions; matrix, $256 \times 224$; field of view, $256 \times 224 \mathrm{~mm}$; slab thickness, $176 \mathrm{~mm}$ ) (Deichmann et al., 2004).

Data analysis. For the pain intensity and anxiety ratings, we first compared the two externally controlled conditions (i.e., other-controlled and computer-controlled) using Student's $t$ test. The analysis revealed that the difference between pain intensity ratings of both conditions did not reach significance. Because we were only interested in neural correlates of behaviorally relevant effects, other- and computer-controlled trials were pooled and considered as "externally controlled trials" in subsequent $t$ test comparisons with selfcontrolled trials.

Neuroimaging data were analyzed using SPM2 (Wellcome Department of Imaging of Imaging Neuroscience, London, UK) (Ashburner et al., 2004). The first five image volumes of each session were discarded to account for T1 relaxation effects. Then the data were realigned to the sixth volume to correct for head motion before statistical analysis. The EPIs were spatially normalized (Friston et al., 1995) to the template of the Montreal Neurological Institute (MNI) (Evans et al., 1993). The normalized EPIs were smoothed using an $8 \mathrm{~mm}$ full-width at half-maximum Gaussian kernel, temporally high-pass filtered (cutoff of $128 \mathrm{~s}$ ), and corrected for temporal autocorrelations using first-order autoregressive modeling.

For each subject, contrast images were calculated for externally and self-controlled pain in which pain stimulation was compared with the $12 \mathrm{~s}$ baseline of each trial, resulting in two contrasts per subject. Furthermore, direct comparisons between self- and externally controlled pain (self $>$ external; external $>$ self) were calculated for each subject. In a separate analysis assessing the negative correlation between subjective pain intensity and brain activity, trial-by-trial intensity ratings were used as a parametric regressor of the categorical "pain - baseline" regressor (pooled across all conditions).

First level contrasts were taken to the second level for the group data analysis using one-sample $t$ tests within a random effects model (Holmes and Friston, 1998). We also computed a second-level regression analysis to explore whether individual differences in brain responses to selfcontrolled compared with externally controlled pain covaried with individual differences in the general belief to have control over one's own life as assessed by the I scale (Levenson, 1981). To further characterize this differential effect, correlations with self-control belief scores were calculated separately for self-controlled and externally controlled pain using the parameter estimates from the right anterolateral prefrontal peak voxel defined by the above correlation analysis with pain intensity ratings $[(x, y, z)$ coordinates of $(36,48,15)]$.

A global threshold was set at $p<0.001$ uncorrected. For analysis of activation within the right anterolateral prefrontal cortex, a small volume correction for multiple comparisons was used. The search volume was defined by a sphere centered around a previously established coordinate [8 mm; coordinates of $(42,48,18)]$ (Kalisch et al., 2005). For the left 
alPFC, a corresponding search volume was defined around the coordinates of $(-42,48,18)(8 \mathrm{~mm})$.

\section{Results}

Behavioral effects of perceived control

In the debriefing session after the experiment, all participants reported they had been convinced that the stimulation had been controlled by another person or by the computer, respectively, in the two externally controlled conditions. Pain intensity and anxiety ratings in the two externally controlled conditions were not significantly different $\left(t_{(11)}=-1.82, p=0.10 ; t_{(11)}=1.03, p=\right.$ 0.32 , respectively), allowing us to pool the data from the two externally controlled conditions for a first analysis. As predicted, self-controlled pain (mean $\pm \mathrm{SD}, 63.74 \pm 9.97$ ) was perceived as less intense than externally controlled pain (mean \pm SD, $68.90 \pm$ $\left.11.03 ; t_{(11)}=-3.06 ; p=0.01\right)$. Likewise, the subjects were less anxious when the stimulation was self-controlled (mean $\pm \mathrm{SD}$, $2.33 \pm 2.31$ vs $4.67 \pm 2.42 ; t_{(11)}=-4.08 ; p=0.002$ ). Hence, perceived control had analgesic and anxiolytic effects, with the anxiolytic effects being relatively stronger than the analgesic effects.

\section{Neural effects of perceived control}

Across conditions, painful electrical stimulation led to bilateral activation in pain-related areas, including insula, secondary somatosensory cortex, anterior cingulate cortex (ACC), and OFC $(p<0.001$ uncorrected) (Table 1$)$.

The increased subjective pain intensity and anxiety in the pooled externally controlled conditions (other-controlled and computer-controlled) was paralleled by higher activation in bilateral OFC and right rostral ACC in the contrast "externally self-controlled pain ( $p<0.001$ uncorrected) (Table 2). Masking with the main effect of pain at a conservative threshold of $p<$ 0.001 (uncorrected) confirmed that the right lateral OFC peak was part of the pain network (Fig. 2). Interestingly, the peak of this activation is close to an area deactivated during relief from pain in a recent study from our group (Seymour et al., 2005).

The opposite comparison, testing for greater activation during self-controlled compared with externally controlled stimulation, revealed activations in right dorsal ACC (dACC), right dorsolateral prefrontal cortex (DLPFC), and bilateral alPFC ( $p<$ 0.001 uncorrected) (Table 3, Fig. 3), areas that have been observed during voluntary reappraisal (Ochsner and Gross, 2005). Importantly, the activation in right alPFC survived correction for multiple comparisons $(z=3.66 ; p=0.009)$ in a predefined search volume, using coordinates from Kalisch et al. (2005) (see Materials and Methods). An activation peak in left alPFC also survived small volume correction in a corresponding left-sided search volume $(z=3.63 ; p=0.009)$.

In a subsequent step, we addressed the question whether any of these areas showed significant differences in activity between the two externally controlled conditions (other-controlled and computer-controlled). To maximize statistical power in addressing this question, we used a hierarchical

\section{externally-controlled pain > self-controlled pain (masked with main effect of pain)}
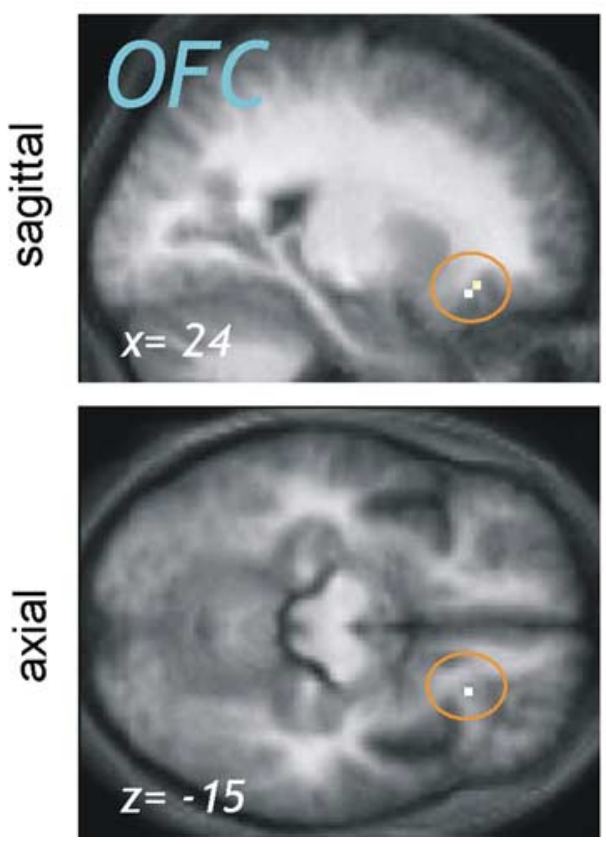

Figure 2. Brain responses to externally controlled compared with self-controlled pain (masked with main effect of pain). To identify pain-related brain regions that were less active when the painful stimulation was perceived as controllable, the contrast "externally $>$ selfcontrolled pain" ( $p<0.001$ uncorrected) was masked by the main effect of pain ( $p<0.001$ uncorrected). A significant reduction in pain-related activity under perceived control was observed in the right lateral OFC [peak voxel, coordinates of $(24,27,-15)]$.

Table 3. Brain responses to self-controlled compared with externally controlled pain ( $p<0.001$ uncorrected)

\begin{tabular}{|c|c|c|c|c|c|c|c|}
\hline \multirow[b]{2}{*}{ Brain region } & \multirow[b]{2}{*}{ Laterality } & \multirow[b]{2}{*}{ Brodmann area } & \multicolumn{3}{|c|}{ MNI coordinates } & \multirow[b]{2}{*}{ Cluster size (voxel) } & \multirow[b]{2}{*}{ Zscore } \\
\hline & & & $x$ & $y$ & $z$ & & \\
\hline \multirow[t]{3}{*}{ ACC/SMA } & $\mathrm{R}$ & 6 & 9 & 12 & 54 & \multirow[t]{3}{*}{313} & 4.77 \\
\hline & $\mathrm{L}$ & 32 & -3 & 15 & 48 & & 4.65 \\
\hline & $\mathrm{L}$ & 32 & -9 & 12 & 42 & & 4.63 \\
\hline \multirow[t]{5}{*}{ DLPFC } & $\mathrm{R}$ & 9 & 33 & 33 & 39 & \multirow[t]{3}{*}{33} & 4.4 \\
\hline & $\mathrm{R}$ & 9 & 30 & 42 & 42 & & 3.78 \\
\hline & $\mathrm{R}$ & 9 & 39 & 39 & 39 & & 3.34 \\
\hline & $\mathrm{R}$ & 46 & 27 & 51 & 33 & 4 & 3.6 \\
\hline & $\mathrm{R}$ & 45 & 45 & 45 & 30 & 6 & 3.2 \\
\hline \multirow[t]{2}{*}{ alPFC } & $\mathrm{R}$ & 46 & 48 & 51 & 12 & 4 & 3.97 \\
\hline & $\mathrm{L}$ & 46 & -39 & 54 & 21 & 5 & 3.63 \\
\hline SMA & $\mathrm{L}$ & 6 & -12 & -6 & 63 & 16 & 3.75 \\
\hline Inferior parietal lobe/SII & $\mathrm{L}$ & 40 & -48 & -36 & 45 & 54 & 3.73 \\
\hline \multirow[t]{3}{*}{ SII } & $\mathrm{R}$ & 2 & 45 & -36 & 54 & 21 & 3.44 \\
\hline & $\mathrm{R}$ & 2 & 54 & -33 & 33 & 6 & 3.61 \\
\hline & $\mathrm{R}$ & 2 & 48 & -33 & 45 & & 3.40 \\
\hline \multirow[t]{2}{*}{ Operculum } & $\mathrm{L}$ & 48 & -45 & -27 & 21 & 5 & 3.43 \\
\hline & $\mathrm{R}$ & 48 & 51 & 6 & 12 & 1 & 3.19 \\
\hline Superior temporal lobe & $\mathrm{L}$ & 42 & -60 & -30 & 21 & 4 & 3.42 \\
\hline Insula & $\mathrm{L}$ & 48 & -36 & 12 & 9 & 2 & 3.33 \\
\hline Premotor cortex & $\mathrm{L}$ & 8 & -12 & 27 & 51 & 1 & 3.31 \\
\hline \multirow[t]{2}{*}{ Cerebellum } & $\mathrm{R}$ & 18 & 15 & -66 & -12 & 3 & 3.26 \\
\hline & $\mathrm{R}$ & 19 & 27 & -60 & -24 & 1 & 3.17 \\
\hline
\end{tabular}

L, Left; $R$, right; SMA, supplementary motor area; SIl, secondary somatosensory cortex. $p<0.001$ uncorrected at voxel level; voxel size, $2 \times 2 \times 2 \mathrm{~mm}$. analysis in which we restricted the contrast "other-controlled versus computer-controlled pain" to those areas that showed a difference between the self-controlled and the externally controlled conditions (see results above). This was implemented by 


\section{self-controlled > externally-controlled pain}
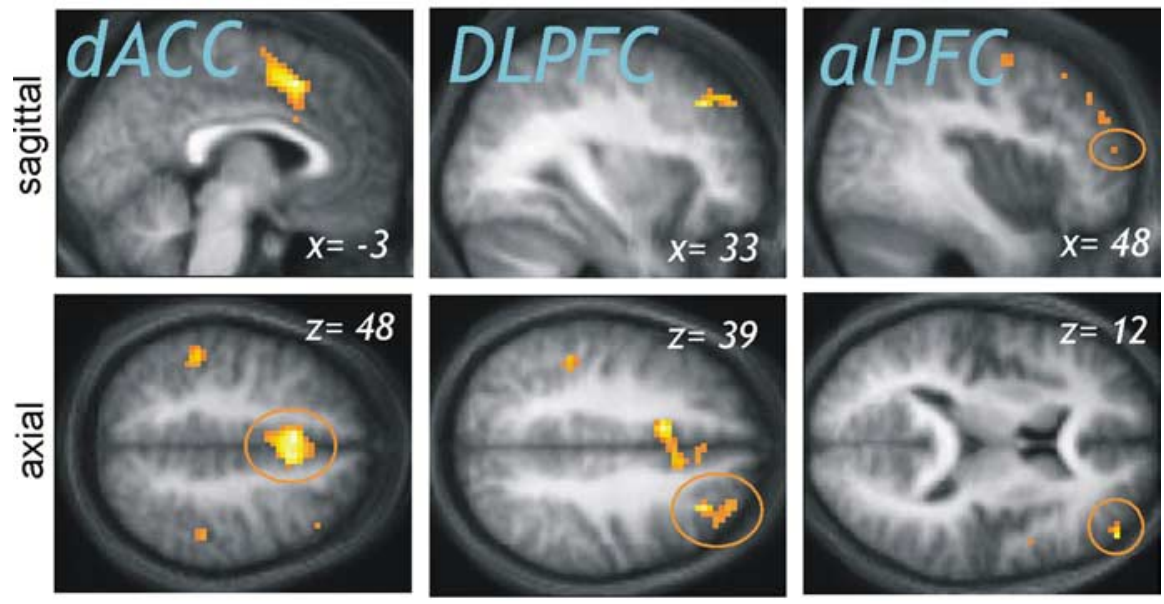

Figure 3. Brain responses to self-controlled compared with externally controlled pain. The dACC [coordinates of $(-3,15,48)]$, DLPFC [coordinates of $(33,33,39)]$, and aIPFC [coordinates of $(48,51,12)$; also left coordinates, not shown] showed significantly greater activity when participants were able to stop the painful stimulation compared with the condition in which pain was uncontrollable ( $p<0.001$ uncorrected). For display purposes, the results are superimposed on the mean structural scan of the 12 participants.

Table 4. Brain areas showing a significant negative correlation with trial-by-trial ratings of subjective pain intensity $(p<0.001$ uncorrected)

\begin{tabular}{|c|c|c|c|c|c|c|c|}
\hline \multirow[b]{2}{*}{ Brain region } & \multirow[b]{2}{*}{ Laterality } & \multirow[b]{2}{*}{ Brodmann area } & \multicolumn{3}{|c|}{ MNI coordinates } & \multirow[b]{2}{*}{ Cluster size (voxel) } & \multirow[b]{2}{*}{ Zscore } \\
\hline & & & $x$ & $y$ & $Z$ & & \\
\hline \multirow[t]{2}{*}{ Fusiform gyrus } & $\mathrm{R}$ & 19 & 30 & -72 & -12 & 16 & 3.99 \\
\hline & $\mathrm{L}$ & 20 & -33 & -30 & -15 & 4 & 3.79 \\
\hline SII & $\mathrm{R}$ & 48 & 51 & -45 & 33 & 4 & 3.97 \\
\hline \multirow[t]{2}{*}{$\mathrm{ACC}$} & $\mathrm{L}$ & 32 & -12 & 21 & 30 & 19 & 3.79 \\
\hline & $\mathrm{R}$ & 24 & 9 & 3 & 33 & 6 & 3.51 \\
\hline \multirow[t]{6}{*}{ Temporal lobe } & $\mathrm{L}$ & 21 & -57 & -57 & 18 & 9 & 3.75 \\
\hline & $\mathrm{L}$ & 22 & -60 & -42 & 9 & 3 & 3.48 \\
\hline & $\mathrm{R}$ & 22 & 57 & -45 & 12 & 3 & 3.32 \\
\hline & $\mathrm{R}$ & 21 & 60 & 0 & -12 & 1 & 3.1 \\
\hline & $\mathrm{R}$ & 37 & 51 & -54 & -3 & 4 & 3.4 \\
\hline & $\mathrm{R}$ & 20 & 51 & -9 & -27 & 1 & 3.16 \\
\hline \multirow[t]{3}{*}{ MPFC } & $\mathrm{R}$ & 10 & 15 & 54 & 21 & 4 & 3.65 \\
\hline & $\mathrm{L}$ & 32 & -15 & 45 & 30 & 2 & 3.21 \\
\hline & $\mathrm{L}$ & 32 & -6 & 27 & 39 & 1 & 3.15 \\
\hline \multirow[t]{2}{*}{ DLPFC } & $\mathrm{R}$ & 46 & 36 & 39 & 24 & 1 & 3.55 \\
\hline & $\mathrm{L}$ & 46 & -27 & 42 & 24 & 9 & 3.47 \\
\hline \multirow[t]{3}{*}{ alPFC } & $\mathrm{R}$ & 46 & 36 & 48 & 15 & 18 & 3.52 \\
\hline & $\mathrm{R}$ & 46 & 30 & 54 & 18 & & 3.47 \\
\hline & $\mathrm{L}$ & 46 & -30 & 48 & 12 & 2 & 3.16 \\
\hline VLPFC & $\mathrm{R}$ & 45 & 54 & 27 & 6 & 3 & 3.48 \\
\hline Operculum & $\mathrm{L}$ & 48 & -36 & 15 & 30 & 4 & 3.45 \\
\hline Occipital lobe & $\mathrm{L}$ & 18 & -27 & -90 & 0 & 2 & 3.16 \\
\hline
\end{tabular}

L, Left; R, right; SII, secondary somatosensory cortex; MPFC, medial prefrontal cortex; VLPFC, ventrolateral prefrontal cortex. $p<0.001$ uncorrected at voxel level; voxel size, $2 \times 2 \times 2 \mathrm{~mm}$.

taking the results from the "self - external" contrast as an inclusive mask for comparing the other- and computer-controlled conditions (note that these contrasts are statistically orthogonal). Despite the reduction in search volume and increase in power, we found no differences between the two externally controlled conditions in alPFC, DLPFC, or dACC. Because pain and anxiety ratings were also not different between the two externally controlled conditions (see above), this suggests that a common neural core mechanism mediates the effects of perceived control, regardless of the external locus of control (LOC).
In combination with the behavioral results, these findings suggest that activation in dorsal prefrontal regions is related to the analgesic effect of perceived control. To further test this, we performed a regression analysis on pain intensity ratings asking whether any of the prefrontal regions identified above was inversely related with pain intensity. Specifically, we used trial-by-trial pain ratings as a parametric modulator of the categorical pain regressor in a separate model. Across conditions, pain ratings were negatively correlated with activation in $\mathrm{dACC}$ and right alPFC ( $p<0.001$ uncorrected) (Table 4, Fig. $4 a$ ). The activation peak in dACC was located ventrally adjacent to the AACC activation observed for "self-controlled externally controlled pain," whereas the activation in right alPFC survived small volume correction in the same predefined search volume as used above $(z=3.20$; $p=0.042)$. In contrast, left alPFC did not show a negative correlation with pain ratings. The correlation analyses thus corroborated the role of brains regions implicated previously in voluntary reappraisal, in particular the right alPFC, for controlinduced analgesia.

\section{Role of locus of control}

Individual differences in coping behavior can partly be explained by trait-like differences in the tendency to perceive oneself as having control. According to Rotter (1966), individuals with an internal LOC tend to believe that environmental events are a consequence of their behavior, whereas those with an external LOC explain events with reference to luck or fate or consider them to be controlled by powerful others. Individuals with an internal LOC, and hence a strong belief to have control over life, usually have weaker stress responses than individuals with an external LOC, i.e., with a weak control belief (Kirkcaldy et al., 1999; Beekman et al., 2000; Bollini et al., 2004). However, in situations in which exertion of control is obviously not possible, individuals with an internal LOC show greater stress responses than individuals with an external LOC (Lundberg and Frankenhaeuser, 1978). These findings once more highlight the importance of control perception as a mediator of coping and predict an interaction between control belief and controllability that could affect pain perception and related brain activity.

We therefore also investigated whether control-related brain activity was affected by the individual trait-like belief to have general control over one's own life. In a group-level regression analysis, individual control belief scores were used as a regressor on whole-brain contrast maps from the contrast "selfcontrolled - externally controlled pain." Across subjects, the 
degree of general control belief was highly correlated with activation in right, but not left, alPFC $[p<0.001$ uncorrected; coordinates of $(30,48,21) ; z=4.62$; cluster size, 65 voxels] (Table 5, Fig. $4 a, b$ ). As in the analyses above, the right alPFC activation survived a hypothesis-driven small volume correction $(z=4.62 ; p<0.001)$. Figure $4 a$ illustrates the overlap between this activation cluster and the right alPFC area negatively correlated with pain intensity, as identified above.

Importantly, the correlation with the degree of general control belief was attributable to varying right alPFC activation in the externally controlled condition (Fig. $4 c$ ) but not in the self-controlled condition (Fig. 4d). That is, during selfcontrolled pain, participants engaged the right alPFC regardless of the strength of their general control belief (Fig. 4d). If, however, there was strong objective evidence against controllability (i.e., when the stimulation was externally controlled), activation in right alPFC decreased as a linear function of general control belief (Fig. 4c). In other words, in individuals with an internal locus of control, right alPFC was more strongly deactivated when pain was uncontrollable than in individuals with an external locus of control.

\section{Discussion}

The results of our study show that painful stimulation under conditions of perceived control activates areas that are involved in voluntary reappraisal (Ochsner and Gross, 2005) and, more generally, in highlevel (i.e., conscious and effortful) appraisal processes (Kalisch et al., 2006a) and that activation in these areas is negatively correlated to subjective pain intensity. Our results are therefore consistent with an important role of high-level appraisal in mediating the analgesic effect of perceived control. At a neural level, they support a role for the right alPFC, an area that we proposed previously as critical for voluntary reappraisal (Kalisch et al., 2006b). A secondary, but nonetheless intriguing, finding is that subjects with a strong belief in having control over life (i.e., with an internal locus of control) activated the alPFC less when they had no control over the painful stimulation. Because such a situation prohibits the use of control-based reappraisal, this finding can be interpreted as additional evidence for an involvement of the right alPFC in this function.

In line with our self report data, previous behavioral studies have shown that perceived control decreases the subjective pain intensity and increases pain tolerance (Staub et al., 1971; Maier and Watkins, 1998; Feldner and Hekmat, 2001) (but see Janssen et al., 2004; Salomons et al., 2004). As a possible mechanism, it has been suggested that perceived control exerts its effect on pain

b.

C.

\section{a. Overlap in alPFC: negative correlation with pain intensity (red) and positive correlation of self-control belief with self>external (yellow)}
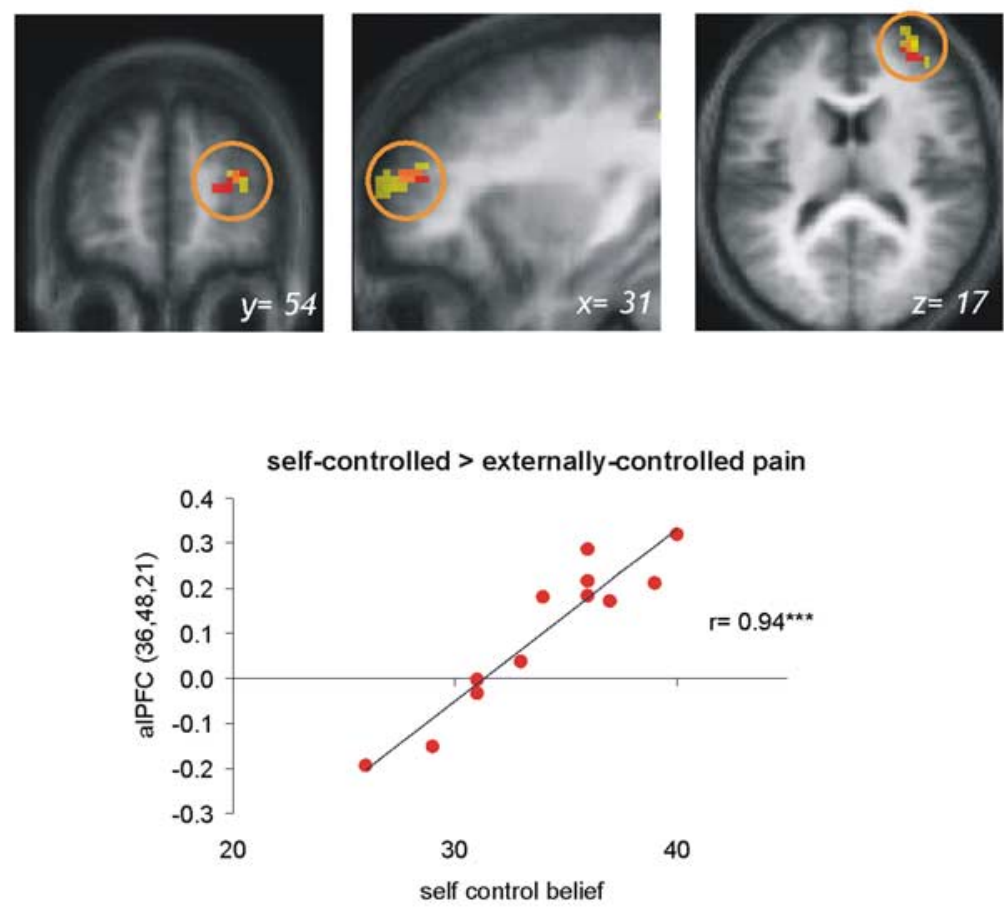

externally-controlled pain

d.

self-controlled pain
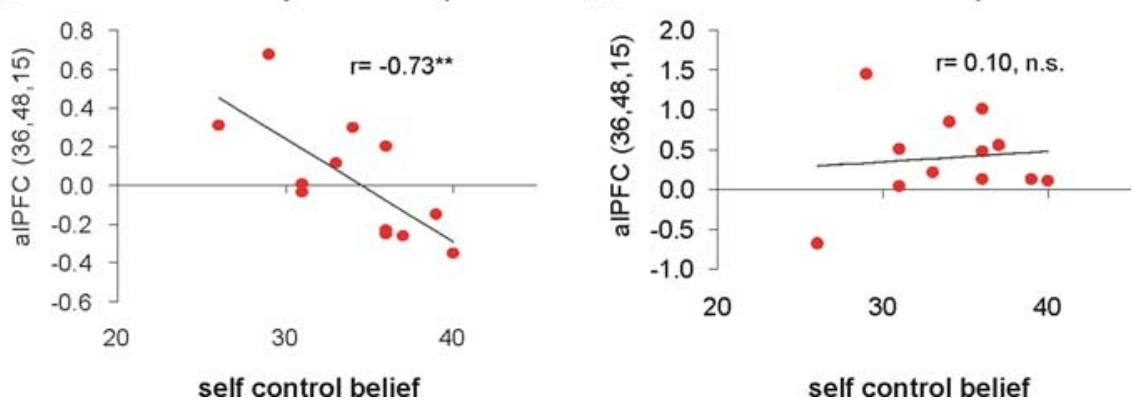

self control belief

Figure 4. Pain intensity and control-related activations in right alPFC. $\boldsymbol{a}$, "Control believers" showed a greater difference in activation between self-controlled and externally controlled pain in right anterolateral prefrontal cortex area [yellow; $p<0.001$; minimum cluster extent, 10 voxels; peak voxel coordinates of $\left.(36,48,21) ;{ }^{* * *} p<0.001\right]$. This activation cluster overlapped with the region that was negatively correlated with subjective pain intensity [red; $p<0.001$; minimum cluster extent, 10 voxels; peak voxel coordinates of $(36,48,15)]$. The results are superimposed on the mean structural scan of the 12 participants. $\boldsymbol{b}$, The activation in right alPFC for self versus external control of pain correlated highly significantly $(r=0.94 ; p<0.001)$ with the general belief of the participants to have control over their lives. $c$, When pain was externally controlled, right alPFC activation was negatively correlated with control belief $(r=-0.73 ; p<0.01)$. $\boldsymbol{d}$, In contrast, control belief did not have a significant impact on the activation of this region when the pain was controllable $(r=0.1)$.

by interacting with anxiety. According to this hypothesis, anxiety-associated arousal amplifies nociceptive responses and perceived control alleviates pain by reducing anxiety (for a discussion, see Arntz and Schmidt, 1989). Our observation that lower pain intensity was paralleled by lower anxiety is in line with this idea. However, an extensive review of the literature on anxiety and pain suggests that the pain-alleviating effect of perceived control is not necessarily accompanied by a reduction in arousal or anxiety and that anxiety reduction does not necessarily reduce pain (Arntz and Schmidt, 1989). A dissociation between pain and anxiety is particularly obvious in fear-induced hypoalgesia (Bolles and Fanselow, 1980; Fanselow, 1986) in which the neces- 
Table 5. Brain areas showing a correlation between the general belief in self-control and the differential effect (self $>$ external) during painful stimulation $(p<0.001$ uncorrected)

\begin{tabular}{|c|c|c|c|c|c|c|c|}
\hline \multirow[b]{2}{*}{ Brain region } & \multirow[b]{2}{*}{ Laterality } & \multirow[b]{2}{*}{ Brodmann area } & \multicolumn{3}{|c|}{ MNI coordinates } & \multirow[b]{2}{*}{ Cluster size (voxel) } & \multirow[b]{2}{*}{ Zscore } \\
\hline & & & $x$ & $y$ & $z$ & & \\
\hline \multirow[t]{2}{*}{ alPFC } & $\mathrm{R}$ & 46 & 36 & 48 & 21 & \multirow[t]{2}{*}{65} & 4.62 \\
\hline & $\mathrm{R}$ & 46 & 33 & 57 & 15 & & 4.14 \\
\hline Premotor cortex & $\mathrm{R}$ & 8 & 24 & 18 & 60 & 4 & 4.21 \\
\hline \multirow[t]{3}{*}{ Occipital lobe } & $\mathrm{L}$ & 18 & -15 & -96 & 0 & 1 & 3.73 \\
\hline & $\mathrm{L}$ & 19 & -45 & -72 & -21 & 2 & 3.64 \\
\hline & $\mathrm{R}$ & 37 & 42 & -72 & 9 & 1 & 3.15 \\
\hline MI & $\mathrm{L}$ & 4 & -6 & -18 & 69 & 3 & 3.46 \\
\hline SMA & $\mathrm{R}$ & 6 & 27 & -21 & 63 & 5 & 3.33 \\
\hline Posterior parietal lobe & $\mathrm{R}$ & 7 & 15 & -66 & 66 & 1 & 3.28 \\
\hline Posterior ACC & $\mathrm{L}$ & 23 & -6 & -24 & 33 & 2 & 3.22 \\
\hline Thalamus & $\mathrm{L}$ & & -12 & -27 & 9 & 1 & 3.18 \\
\hline
\end{tabular}

L, Left; R, right; DMPFC, dorsomedial prefrontal cortex; MI, primary motor cortex; SMA, supplementary motor area. $p<0.001$ uncorrected at voxel level; voxel size, $2 \times 2 \times 2 \mathrm{~mm}$.

sity to produce a flight-or-fight response leads to a shutdown of nociception (for replication in humans, see Rhudy et al., 2004). In this context, it is worth mentioning that, in our study, the differential ratings for anxiety and pain ratings (i.e., "externally controlled - self-controlled") showed a trend to be negatively correlated $(r=-0.56 ; p=0.06)$.

Alternatively, Miller (1979) proposed that perceived control can lead to a reduction of subjective pain because it allows individuals to rely on a stable, reliable source of coping (i.e., his or her own response) that can modify the aversive event or its impact. Therefore, future danger and discomfort can reliably be kept below an acceptable level. According to this perspective, perceived control triggers reappraisal processes that change the significance or meaning of the pain (Arntz and Schmidt, 1989). This change in motivational value may occur unconsciously (low-level) or also consciously (high-level) (Leventhal and Scherer, 1987; Robinson, 1998), such as when taking the explicit form of, for instance, "I can stop the pain whenever I want, so it doesn't bother me that much." An interesting implication of this theoretical viewpoint is that it predicts control-induced attenuations in affective-evaluative but not necessarily sensory-discriminative areas of the pain matrix.

Based on the assumption that controllable pain induces voluntary reappraisal, we predicted and found higher activity of dorsal medial and lateral prefrontal cortex, in particular right alPFC, during self-controlled compared with externally controlled pain (Fig. 3). [A separate line of research in rodents has established an important role of the ventral medial prefrontal cortex. For comments, see supplemental data (available at www. jneurosci.org as supplemental material).] A possible alternative explanation for the observed prefrontal activations, however, is that the self-controlled, but not the externally controlled, condition was also associated with the instruction to exert control if needed. Exerting or preparing to exert control is a cognitive task that includes monitoring, decision-making, and response-preparation components and may rely on a prefrontal executive control network (Badre and Wagner, 2004; Miller and D'Esposito, 2005). Also, the self-controlled condition was different from the externally controlled condition in that it was essentially a somatosensory-motor task (in which button responses were cued by intolerable pain), whereas the externally controlled condition was a visuomotor task (in which button responses were cued by a visual signal). Finally, this implies that, in the self-controlled condition, subjects probably tried to inhibit a motor response that would terminate pain. In contrast, in the externally controlled condition, the but- ton press was externally triggered and without effect on the painful stimulation, making motor inhibition a less relevant component in the externally controlled condition. We cannot exclude that these task differences may have contributed to activation differences in the PFC. Indeed, the observed activations in the contralateral supplementary motor area in the selfcontrolled condition (Table 3 ) is compatible with a motor inhibition component (Toma et al., 1999).

More direct evidence, however, that some of the prefrontal activations observed during self-controlled trials are related to reappraisal comes from two observations. First, activations in right dACC and right (but not left) alPFC were inversely related to subjective pain intensity (Tables 4, 5; Fig. 4a). This is consistent with the presumed analgesic effects of controlbased reappraisal and speaks against the motor inhibition hypothesis, because motor inhibition should be stronger under more intense pain. Second, right (but not left) alPFC activation in the externally controlled condition was not generally reduced (as might be expected if it reflected the cognitive task of exerting or preparing to exert control) but varied with the level of general control belief (Fig. 4).

In addition to prefrontal activations, cognitive modulation of pain by various methods can result in deactivation of pain processing areas (Petrovic et al., 2000; Bantick et al., 2002; Salomons et al., 2004; Wager et al., 2004; Wiech et al., 2005; Bingel et al., 2006). We found no evidence for a deactivation of lower pain processing areas or somatosensory cortex or for activation of descending antinociceptive systems such as periaqueductal gray or rostral ACC (Tracey et al., 2002; Wager et al., 2004). In contrast, we observed attenuation of pain-related lateral OFC activity in self-controlled compared with externally controlled pain (Table 2). This result is particularly interesting because OFC activation is not only observed during pain (Tracey et al., 2000; Wiech et al., 2005) but more generally during affective states (O'Doherty, 2004). Lateral foci in particular are typical for aversive affective states (O'Doherty et al., 2001), and pain-related lateral OFC activity correlates with fear of pain (Ochsner et al., 2006). This suggests that lateral OFC attenuated by control is involved in the emotional-motivational appraisal of pain rather than in encoding its sensory properties, a viewpoint in agreement with the general role of OFC in representing value information (Schoenbaum and Roesch, 2005). This observation (and the absence of effects in sensory-discriminative pain processing areas) further supports a reappraisal view of control in which control modifies the emotional meaning of a painful stimulus rather than its sensory properties. We note that a dissociation of primary versus higher-order processing areas has also been reported under hypnotic analgesia (Rainville et al., 1997) in which analgesia was induced by a specific type of hypnosis (Kiernan et al., 1995) that may share cognitive processes with reappraisal. It should be mentioned, however, that the absence of effects in sensory-discriminative pain processing areas may also be related to only moderate reductions in subjective pain compared with other studies (Bantick et al., 2002; Wager et al., 2004).

Individuals with a strong internal locus of control normally show attenuated stress responses compared with individuals with an external LOC (Kirkcaldy et al., 1999; Beekman et al., 2000; 
Bollini et al., 2004) but show greater stress responses than these when control is made impossible (Lundberg and Frankenhaeuser, 1978). This pattern may result from individuals with an internal LOC adopting powerful control-based reappraisal schema ("This problem doesn't bother me, because I can solve it if I want"), which they use habitually to cope with challenging situations. Individuals with an external LOC may be able to use such reappraisal strategies in those few situations only in which strong objective evidence for controllability exists. They may therefore rely on alternative reappraisal schemata that acknowledge the influence of external factors, and this may result in greater stress responses. Those alternative reappraisals can be advantageous, however, in situations in which there is strong objective evidence against controllability and control-based reappraisals would lead to cognitive dissonance. In such situations, individuals with an internal LOC may experience problems exchanging established reappraisal schemes against alternative reappraisals, resulting in augmented stress responses. This view fits with our observation that, in the externally controlled condition, right alPFC activation was reduced more strongly the higher the subjects' general belief to have control over their lives. We propose that reduced right alPFC activation could reflect a "breakdown" of a habitual reappraisal strategy. A caveat, however, is that we did not find a corresponding interaction between control belief and subjective pain intensity or anxiety in our data, possibly attributable to the small sample size $(n=12)$.

In conclusion, we described a neural basis for the analgesic effects of perceived control as well as a potential mechanism underlying the sometimes maladaptive effects of a strong internal control belief. This study therefore advances our knowledge about the neural mechanisms controlling pain and mediating successful coping. Successful recruitment of the right alPFC is likely to be a key factor for success in cognitive therapeutic approaches enhancing the patient's sense of self-efficacy and mastery (Bandura, 1977) but also in more recent acceptance-based treatments that stress the importance of not trying to control an uncontrollable situation (Hayes and Bissett, 1999; McCracken and Eccleston, 2005). Future studies may evaluate the use of right alPFC activation as an objective biological marker for treatment response or as a target for therapeutic fMRI biofeedback (Weiskopf et al., 2003; deCharms et al., 2005).

\section{References}

Arntz A, Schmidt AJM (1989) Perceived control and the experience of pain. In: Stress, personal control and health (Steptoe A, Appels A, eds), pp 131-162. Brussels: Wiley.

Ashburner J, Friston KJ, Penny W (2004) Imaging neuroscience-theory and analysis. In: Human brain function (Frackowiak RS, Friston KJ, Frith C, Dolan RJ, Price CJ, eds), pp 599-1104. San Diego: Academic.

Badre D, Wagner AD (2004) Selection, integration, and conflict monitoring: assessing the nature and generality of prefrontal cognitive control mechanisms. Neuron 41:473-487.

Bandura A (1977) Self-efficacy: toward a unifying theory of behavioral change. Psychol Rev 84:191-215.

Bantick SJ, Wise RG, Ploghaus A, Clare S, Smith SM, Tracey I (2002) Imaging how attention modulates pain in humans using functional MRI. Brain 125:310-319.

Beekman ATF, de Beurs E, van Balkom AJLM, Deeg DJH, van Dyck R, van Tilburg W (2000) Anxiety and depression in later life: co-occurrence and communality of risk factors. Am J Psychiatry 157:89-95.

Bingel U, Lorenz J, Schoell E, Weiller C, Büchel C (2006) Mechanisms of placebo analgesia: rACC recruitment of a subcortical antinociceptive network. Pain 120:8-15.

Bolles RC, Fanselow MS (1980) A perceptual-defensive-recuperative model of fear and pain. Behav Brain Sci 3:291-323.

Bollini AM, Walker EF, Hamann S, Kestler L (2004) The influence of per- ceived control and locus of control on the cortisol and subjective responses to stress. Biol Psychol 67:245-260.

deCharms RC, Maeda F, Glover GH, Ludlow D, Pauly JM, Soneji D, Gabrieli JD, Mackey SC (2005) Control over brain activation and pain learned by using real-time functional MRI. Proc Natl Acad Sci USA 102:18626-18631.

Deichmann R, Gottfried JA, Hutton C, Turner R (2003) Optimized EPI for fMRI studies of the orbitofrontal cortex. NeuroImage 19:430-441.

Deichmann R, Schwarzbauer C, Turner R (2004) Optimisation of the 3D MDEFT sequence for anatomical brain imaging: technical implications at 1.5 and $3 \mathrm{~T}$. NeuroImage 21:757-767.

Evans AC, Collins DL, Mills SR, Brown ED, Kelly RL, Peters TM (1993) 3D statistical neuroanatomical models form 305 MRI volumes. Proc IEEE $1: 1813-1817$.

Fanselow MS (1986) Conditioned fear-induced opiate analgesia: a competing motivational state theory of stress analgesia. Ann NY Acad Sci 467:40-54.

Feldner MT, Hekmat H (2001) Perceived control over anxiety-related events as a predictor of pain behaviors in a cold pressor task. J Behav Ther Exp Psychiatry 32:191-202.

Friston KJ, Ashburner J, Frith CD, Poline JB, Heather JD, Frackowiak RS (1995) Spatial registration and normalization of images. Hum Brain Mapp 2:1-25.

Gross JJ (2002) Emotion regulation: affective, cognitive, and social consequences. Psychophysiology 39:281-291.

Hayes SC, Bissett RT (1999) The impact of acceptance versus control rationales on pain tolerance. Psychol Rec 49:3-47.

Holmes AP, Friston KJ (1998) Generalisability, random effects and population inference. NeuroImage 7:S754.

Janssen SA, Spinhoven P, Arntz A (2004) The effects of failing to control pain: an experimental investigation. Pain 107:227-233.

Kalisch R, Wiech K, Critchley HD, Seymour B, O'Doherty JP, Oakley DA, Allen P, Dolan RJ (2005) Anxiety reduction through detachment: subjective, physiological, and neural effects. J Cogn Neurosci 17:874-883.

Kalisch R, Wiech K, Critchley HD, Dolan RJ (2006a) Levels of appraisal: a medial prefrontal role in cognitive appraisal of emotional material. NeuroImage 30:1458-1466.

Kalisch R, Wiech K, Herrmann K, Dolan RJ (2006b) Neural correlates of self distraction from anxiety and a process model of cognitive emotion regulation. J Cogn Neurosci 18:1266-1276.

Kiernan BD, Dane JR, Phillips LH, Price DD (1995) Hypnotic analgesia reduces R-III nociceptive reflex: further evidence concerning the multifactorial nature of hypnotic analgesia. Pain 60:39-47.

Kirkcaldy BD, Cooper CL, Furnham AF (1999) The relationship between type A, internality-externality, emotional distress and perceived health. Pers Individ Dif 26:223-235.

Levenson H (1981) Differentiating among internality, powerful others, and chance. In: Research with the locus of control construct (Lefcourt HM, ed), pp 15-63. New York: Academic.

Leventhal H, Scherer KR (1987) The relationship of emotion to cognition: a functional approach to a semantic controversy. Cogn Emot 1:3-28.

Lundberg U, Frankenhaeuser M (1978) Psychophysiological reactions to noise as modified by personal control over noise intensity. Biol Psychol 6:51-59.

Maier SF, Watkins LR (1998) Stressor controllability, anxiety and serotonin. Cogn Ther Res 22:595-613.

McCracken LM, Eccleston C (2005) A prospective study of acceptance of pain and patient functioning with chronic pain. Pain 118:164-169.

Miller BT, D'Esposito M (2005) Searching for “the top" in top-down control. Neuron 48:535-538.

Miller SM (1979) Controllability and human stress: method, evidence, and theory. Behav Res Ther 17:287-304.

Mohr C, Binkofski F, Erdmann C, Büchel C, Helmchen C (2005) The anterior cingulate cortex contains distinct areas dissociating external from self-administered painful. Pain 114:347-357.

O’Doherty J, Kringelbach ML, Rolls ET, Hornak J, Andrews C (2001) Abstract reward and punishment representations in the human orbitofrontal cortex. Nat Neurosci 4:95-102.

O’Doherty JP (2004) Reward representations and reward-related learning in the human brain: insights from neuroimaging. Curr Opin Neurobiol 14:769-776.

Ochsner KN, Gross JJ (2005) The cognitive control of emotion. Trends Cogn Sci 9:242-249. 
Ochsner KN, Ludlow DH, Knierim K, Hanelin J, Ramachandran T, Gover GC, Mackey SC (2006) Neural correlates of individual differences in pain-related fear and anxiety. Pain 120:69-77.

Pellino TA, Ward SE (1998) Perceived control mediates the relationship between pain severity and patient satisfaction. J Pain Symptom Manage 15:110-116.

Petrovic P, Petersson KM, Ghatan PH, Stone-Elander S, Ingvar M (2000) Pain-related cerebral activation is altered by a distracting cognitive task. Pain 85:19-30.

Rainville P, Duncan GH, Price DD, Carrier B, Bushnell MC (1997) Pain affect encoded in human anterior cingulate but not somatosensory cortex. Science 277:968-971.

Robinson MD (1998) Running from William James' bear: a review of preattentive mechanisms and their contributions to emotional experience. Cogn Emot 12:667-696.

Rotter J (1966) Generalized expectancies for internal versus external control of reinforcement. Psychol Monogr 80:1-28.

Rhudy JL, Grimes JS, Meagher MW (2004) Fear-induced hypoalgesia in humans: effects on low intensity thermal stimulation and finger temperature. J Pain 5:458-468.

Salomons TV, Johnstone T, Backonja MM, Davidson RJ (2004) Perceived controllability modulates the neural response to pain. J Neurosci 24:7199-7203.

Scharff L, Turk DC, Marcus DA (1995) The relationship of locus of control and psychosocial-behavioral response in chronic headache. Headache 35:527-533

Schoenbaum G, Roesch M (2005) Orbitofrontal cortex, associative learning, and expectancies. Neuron 47:633-636.

Seymour B, O’Doherty JP, Koltzenburg M, Wiech K, Frackowiak R, Friston K,
Dolan R (2005) Opponent appetitive-aversive neural processes underlie predictive learning of pain relief. Nat Neurosci 8:1234-1240.

Staub E, Tursky B, Schwartz GE (1971) Self-control and predictability: their effects on reactions to aversive stimulation. J Pers Soc Psychol 18:157-162.

Stedman TL (1995) The American heritage Stedman's medical dictionary. Baltimore: Williams and Wilkins.

Toma K, Honda M, Hanakawa T, Okada T, Fukuyama H, Ikeda A, Nishizawa S, Konishi J, Shibasaki H (1999) Activities of the primary and supplementary motor areas increase in preparation and execution of voluntary muscle relaxation: an event-related fMRI study. J Neurosci 19:3527-3534.

Tracey I, Becerra L, Chang I, Breiter H, Jenkins L, Borsook D, Gonzalez RG (2000) Noxious hot and cold stimulation produce common patterns of brain activation in humans: a functional magnetic resonance imaging study. Neurosci Lett 288:159-162.

Tracey I, Ploghaus A, Gati JS, Clare S, Smith S, Menon RS, Matthews PM (2002) Imaging attentional modulation of pain in the periaqueductual gray in humans. J Neurosci 22:2748-2752.

Wager T, Rilling J, Smith EE, Sokolik A, Casey K, Davidson RJ, Kosslyn SM, Rose RM, Cohen JD (2004) Placebo-induced changes in fMRI in the anticipation and experience of pain. Science 303:1162-1167.

Weisenberg M, Wolf Y, Mittwoch T, Mikulincer M, Aviram O (1985) Subject versus experimenter control in the reaction to pain. Pain 23:187-200.

Weiskopf N, Veit R, Erb M, Mathiak K, Grodd W, Goebel R, Birbaumer N (2003) Physiological self-regulation of regional brain activity using realtime functional magnetic resonance imaging (fMRI): methodology and exemplary data. NeuroImage 19:577-586.

Wiech K, Seymour B, Kalisch R, Stephan KE, Koltzenburg M, Driver J, Dolan $\mathrm{R}$ (2005) Modulation of pain processing in hyperalgesia by cognitive demand. NeuroImage 27:59-69. 